\title{
Antihypertensive effect of a fixed-dose combination of losartan / hydrochlorothiazide in patients with uncontrolled hypertension: a multicenter study
}

\author{
Tatsuo Hosoya $\cdot$ Satoru Kuriyama $\cdot$ Iwao Ohno $\cdot$ Tetsuya Kawamura \\ Makoto Ogura • Masato Ikeda • Masahiro Ishikawa · Fumihiro Hayashi • \\ Tatsuya Kanai · Haruo Tomonari - Michimasa Soejima • Kiyoaki Akaba • \\ Goro Tokudome
}

Received: 31 August 2011/Accepted: 10 November 2011/Published online: 30 November 2011

(C) The Author(s) 2011. This article is published with open access at Springerlink.com

\begin{abstract}
Background Achieving adequate blood pressure (BP) control often requires more than one antihypertensive agent. The purpose of this study was to determine whether a fixed-dose formulation of losartan (LOS) plus hydrochlorothiazide (HCTZ) (LOS/HCTZ) is effective in achieving a greater BP lowering in patients with uncontrolled hypertension.

Methods The study was a prospective, multicenter, observational trial exploring the antihypertensive effect of a single
\end{abstract}

The list of authors on behalf of the JOINT Study Group is listed in "Appendix".

T. Hosoya $\cdot$ S. Kuriyama $\cdot$ I. Ohno $\cdot$ T. Kawamura $\cdot$

M. Ogura · M. Ikeda · M. Ishikawa · F. Hayashi · G. Tokudome

Department of Kidney and Hypertension, Jikei University

School of Medicine, Tokyo, Japan

S. Kuriyama $(\square)$

Division of Nephrology, Saiseikai Central Hospital,

1-4-17 Mita, Minato-ku, Tokyo 108-0073, Japan

e-mail: kuriyamas218@yahoo.co.jp

M. Ishikawa

Kawaguchi Medical Center, Saitama, Japan

F. Hayashi · G. Tokudome

Tokyu Hospital, Tokyo, Japan

T. Kanai

Kanai Naika Clinic, Tokyo, Japan

H. Tomonari

Tomonari Clinic, Tokyo, Japan

M. Soejima

Soejima Clinic, Tokyo, Japan

K. Akaba

Akaba Clinic, Tokyo, Japan tablet of LOS $50 \mathrm{mg} / \mathrm{HCTZ} 12.5 \mathrm{mg}$. A total of 228 patients whose BP had previously been treated with more than one antihypertensive agents without having achieved BP goal below 130/80 mmHg enrolled in the study.

Results A significant decrease in systolic and diastolic BP was observed in both clinic and home measurement after switching from the previous treatment to LOS/HCTZ. There was a significant decrease in both B-type natriuretic peptide (BNP) and urinary albumin creatinine (Cr) excretion ratio (ACR), especially in patients with elevated values. In contrast, there was a significant increase in serum $\mathrm{Cr}$ concentration in conjunction with a decrease in estimated glomerular filtration rate (eGFR). Overall serum uric acid (UA) concentration increased, whereas in patients with hyperuricemia there was a significant reduction in this value. Conclusion Switching to LOS/HCTZ provides a greater reduction in clinic and home BP in patients with uncontrolled hypertension. This combination therapy may lead to cardio-, reno protection and improve UA metabolism.

Keywords Losartan · Hydrochlorothiazide . Hypertension · BNP · Albuminuria

\section{Introduction}

A plethora of evidence has indicated that strict BP reduction is indispensable to improve patients' prognosis, inadequate control of BP is thus leaving patients at risk of cardiovascular disease, particularly in patients with chronic kidney disease (CKD) and uncontrollable hypertension [1]. Despite the increasing awareness of antihypertensive treatment, only a small proportion of patients achieve the recommended target goals around the world [2-5]. For instance, the BP goals set by hypertension management guidelines in Japan are currently 
being achieved in only about $40 \%$ of treated patients $[2,5]$. Similar low rates of hypertension control have been reported worldwide $[3,4]$. The reason for the inadequacy of controlling hypertension could at least in part be accounted for by physician's insufficient knowledge on how to prescribe appropriate antihypertensive agents.

Through reviewing the literature, Bakris et al. [6] have suggested that in order to achieve lower BP of less than $130 / 80 \mathrm{mmHg}$, more than two drugs are needed in most patients. Indeed, many guidelines for the management of hypertension have recommended that combination of multiple antihypertensive agents with different pharmacological mode of action is more efficacious than a single agent alone [3]. In this context, the combination of an angiotensin II receptor blocker (ARB) and hydrochlorothiazide (HCTZ) has been widely recognized as a preferable prescription, because combining ARB with HCTZ exerts a complementary pharmacological effect by suppressing renin angiotensin system (RAS) with the former and body fluid system with the latter, which provides a greater reduction in BP than either agent alone. LOS combined with the small dose HCTZ as a fixed dose single-tablet formulation, is one such option that has demonstrated substantial antihypertensive effect [7]. LOS is unique in that it is the only ARB that has a uricosuric effect that leads to a decreased serum uric acid (UA) levels. This effect could be mediated by the inhibition of the urate transporter URAT-1 in the renal tubules [8]. Owing to this specific benefit on UA metabolism, LOS has been known to ameliorate diuretic-induced hyperuricemia $[8,9]$.

Despite substantial antihypertensive effect, thiazide diuretics including HCTZ often induce adverse effects such as hypokalemia, impaired glucose tolerance and an increase in serum UA concentration. These side effects of HCTZ could be minimized if prescribed in a lower dosage. A fixed-dose combination formula of LOS $(50 \mathrm{mg}$; the optimal dose) plus a low dose HCTZ (12.5 mg; a half of the optimal dose) (LOS/HCTZ) is thus worth evaluating in terms of BP lowering potency and avoiding side effects.

In the present study, we made an attempt to evaluate the clinical benefit of a single-tablet formulation of LOS/ HCTZ, by conducting a multicenter observational trial, the Jikei Optimal Antihypertensive Treatment (JOINT) study in uncontrolled hypertensive patients.

\section{Methods}

\section{Study subjects}

Eligible patients were men and women between 20 and 75 years of age with essential hypertension and those with CKD with hypertension. Ethnic extraction of all participants was Japanese with all four biological grandparents born in Japan and of Japanese descent. The inclusion criteria were outpatients whose $\mathrm{BP}$ was more than $130 / 80 \mathrm{mmHg}$ despite the antihypertensive agents prescribed for more than 3 months prior to study entry. The exclusion criteria were patients whose serum creatinine (Cr) concentration exceeded $220 \mu \mathrm{mol} / \mathrm{L}$ (compatible with CKD stage 5), those with liver dysfunction (defined as an elevation of aspartate aminotransferase/alanine aminotransferase 3 times higher than the upper normal limit), pregnant, expecting, or lactating women, CKD patients with massive proteinuria of nephrotic range (defined as a daily protein excretion of $3 \mathrm{~g} /$ day or more), and patients whose doctor in charge judged it inappropriate to enroll.

\section{Study protocol}

All institutions received prior ethics committee and or institutional review board approval, and the trial was conducted in accordance with the principles of Good Clinical Practice and the ethical principles of the concurrent Declaration of Helsinki which also protected the privacy of the patients. All patients gave written informed consent before study enrollment. The JOINT was a multicenter observational self-controlled study to evaluate the antihypertensive effect of a fixed-dose combination formulation of LOS/ HCTZ (Clinical trial Number by UMIN 000001950). The study was conducted at 28 centers and clinics for the JOINT study group ("Appendix") in the vicinity of Tokyo, Japan.

Patients were previously treated with either one or more antihypertensive agents on an outpatient basis. The protocol for the administration of LOS/HCTZ was the following. If the patient was being treated with either ARB or calcium channel blocker (CCB) alone or together, LOS/HCTZ was substituted for either drug or the combination. If the patient was being treated with three drugs including RAS inhibitors, the RAS inhibitor was switched to LOS/HCTZ. In all of the protocol patterns, LOS/HCTZ was administered once a day in the morning.

Advices on life-style modification plan were carried out throughout the study. Namely, from the run-in and the observation period, the patients were required to maintain a daily salt intake of $6 \mathrm{~g}$ or less. A protein restriction of $0.6-0.8 \mathrm{~g} / \mathrm{kg} /$ day was also required when the patient's $\mathrm{CCr}$ was below $30 \mathrm{~mL} / \mathrm{min} / 1.73 \mathrm{~m}^{2}$. The other lifestyle modifications included smoking cessation, weight reduction, moderation in alcohol consumption, mild to moderate regular exercise, and reduction in saturated and total fat intake.

\section{Endpoints}

The primary endpoint was the change in clinic systolic and diastolic BP after 6 months of treatment. Secondary endpoints included change in home BP, urinary albumin 
creatinine excretion ratio (ACR), B-type natriuretic peptide (BNP) and serum UA concentration.

BP measurements and laboratory tests

The clinic BP was measured in a sitting position during a morning visit (9-11 am) every 4 weeks. We followed all American Heart Association Recommendations published in 1988 [8, 10] including using a $47 \times 13 \mathrm{~cm}$ cuff and $24 \times 13 \mathrm{~cm}$ bladder to avoid cuff hypertension. The cuff was strictly positioned $2 \mathrm{~cm}$ above the antecubital crease to obtain a similarly leveled complete compression of the brachial artery. All BP values were expressed as the average of two measurements obtained at the same time-point.

Patients were required to measure home $\mathrm{BP}$ in the morning in a sitting position within 30 min after awakening before taking medications in a fasting state. Night time home BP measurement was also required to measure at any given time between supper and bedtime with having patient's habitual drinking unrestricted. BP measuring devices equipped with upper arm cuff were encouraged to use. The averages of several measured values were used for analysis.

Laboratory tests carried out after 6 months of treatment were BNP, serum $\mathrm{Cr}$ concentration, ACR, estimated-GFR (eGFR), serum UA concentration, and others including lipid profiles. The urinary albumin level was determined from a spot urine sample using a turbidimetric immunoassay (SRL, Tokyo, Japan). Plasma BNP was measured using high-sensitivity, noncompetitive radioimmunoassays (Shiono-RIA BNP, Shionogi Inc, Osaka, Japan)

Statistical analyses

The paired student's $t$ test, Wilcoxon's signed rank test, and one-way analysis of variance (ANOVA) and Bonferroni's post hoc test were carried out with JMP 9.0 software. The computer used for the analysis was a Dynabook Satellite 2590X (Toshiba, Tokyo, Japan).

Data are presented as the mean \pm standard deviation (SD) for continuous variables with normal distribution. Continuous variables without normal distribution are presented as median and interquartile range (IQR) with 25 and 75 percentiles. Because of their skewed distribution, logarithmic transformation of BNP and ACR values were performed as the geometric means with $95 \%$ confidence intervals. A $P$ value of less than 0.05 was considered statistically significant.

\section{Results}

Prescription of antihypertensive agents

A total of 277 patients were registered in the JOINT study, of whom 49 were excluded (33 were lost during follow-up,
7 had protocol violations, and 9 had inadequate data for analyses). Consequently a total of 228 patients with clinical index data were included in the analysis. The majority of the patients $(n=142,62 \%)$ had an eGFR more than $60 \mathrm{~mL} / \mathrm{min} / 1.73 \mathrm{~m}^{2}$ (Table 1 ).

The baseline medications were monotherapy in $55 \%$, dual therapy in $32 \%$ and therapy with 3 or more drugs in $13 \%$. The majority of patients were taking ARBs (72\%) or CCBs $(54 \%)$, with only low numbers taking beta-blockers (6\%), alpha-blockers (6\%), or angiotensin converting enzyme inhibitors (ACE-I) $(5 \%)$. At the beginning of the study, almost half of the patients (48\%) switched from ARB to LOS/HCTZ, while $18 \%$ switched from CCB to LOS/HCTZ, $15 \%$ switched from ARB + CCB to LOS/ HCTZ, and $20 \%$ switched to the prescriptions in which one of the pre-prescribed drugs was substituted by LOS/HCTZ.

Changes in clinic and home BP

Figure 1 shows the antihypertensive effect of LOS/HCTZ on clinic BP. After 6 months of switching from the baseline medications to LOS/HCTZ, significant decreases in clinic BP were observed in both systolic (145 \pm 13 to $135 \pm 15 \mathrm{mmHg})$ and diastolic $\mathrm{BP}(87 \pm 9$ to $81 \pm 9$ mmHg, both comparisons $P<0.001)$. The overall achieving rate of BP goal of either systolic BP less than $130 \mathrm{mmHg}$ or diastolic BP less than $80 \mathrm{mmHg}$ was $53 \%$ (120/228 cases).

Decreases in the clinic systolic and diastolic BP were observed in all of the following 3 patterns (Fig. 2); patients switched from ARB to LOS/HCTZ $(145 \pm 12 / 88 \pm 8$ to $134 \pm 12 / 80 \pm 10 \mathrm{mmHg}$, both systolic and diastolic, $P<0.001)$; from CCB to LOS/HCTZ $(147 \pm 11 / 87 \pm 10$ to $134 \pm / 80 \pm 10 \mathrm{mmHg}$, both systolic and diastolic, $P<0.001)$; and from ARB + CCB to LOS/HCTZ + CCB $(140 \pm 11 / 87 \pm 11$ to $131 \pm 9 / 82 \pm 9 \mathrm{mmHg}$, both systolic and diastolic, $P<0.001)$.

Table 1 Patient baseline characteristics $(n=228)$

\begin{tabular}{ll}
\hline Age (years) & $60.3 \pm 11.5$ \\
Gender $($ male/female) & $158(69 \%) / 70(31 \%)$ \\
BMI $\left(\mathrm{kg} / \mathrm{m}^{2}\right)$ & $25.3 \pm 4.4$ \\
Diabetes $(n)$ & $35(15 \%)$ \\
Dyslipidemia $(n)$ & $76(33 \%)$ \\
Heart disease $(n)$ & $8(4 \%)$ \\
CKD stage $(n)$ & \\
$1(\mathrm{eGFR} \geq 90)$ & $23(10 \%)$ \\
$2(60 \leq$ eGFR $<90)$ & $119(52 \%)$ \\
$3(30 \leq$ eGFR $<60)$ & $70(31 \%)$ \\
$4(15 \leq$ eGFR $<30)$ & $11(5 \%)$
\end{tabular}

$B M I$ body mass index, $e G F R$ estimated glomerular filtration rate 
With respect to the difference of patients background classified by $\mathrm{BP}$ response, the responders defined as a reduction in systolic $\mathrm{BP}$ of $\geq 10 \mathrm{mmHg}$, had a greater systolic (responders, $150 \pm 13 \mathrm{mmHg}$ vs. non-responders, $140 \pm 10 \mathrm{mmHg}, P=0.044$ ) and diastolic BP (responders, $88 \pm 9 \mathrm{mmHg}$ vs. non-responders, $86 \pm 10 \mathrm{mmHg}$, $P=0.041)$ at the entry of the trial.

Figure 3 shows the results of home BP measurements. Morning BP was significantly decreased from $142 \pm 12$ / $87 \pm 11 \mathrm{mmHg}$ at baseline to $130 \pm 17 / 80 \pm 11 \mathrm{mmHg}$ (both systolic and diastolic, $P<0.001$ ). Night time BP was also decreased from $137 \pm 12 / 86 \pm 9 \mathrm{mmHg}$ to $124 \pm 10 / 78 \pm 9 \mathrm{mmHg}$ (both systolic and diastolic, $P<0.001)$. The significant $\mathrm{BP}$ reduction was apparent from month 1 and continued throughout the study period of 6 months.

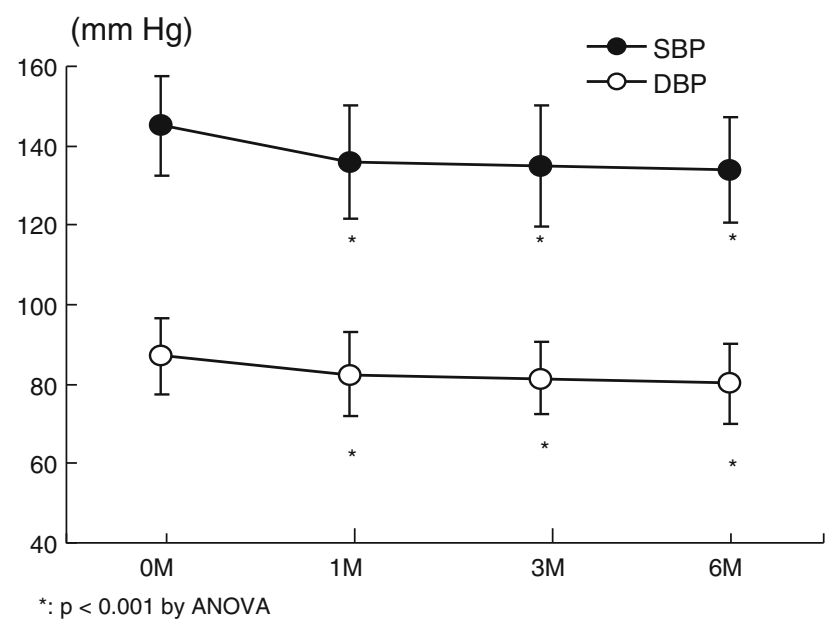

Fig. 1 Effect of LOS/HCTZ on clinic BP (all patients). SBP systolic blood pressure, $D B P$ diastolic blood pressure, LOS/HCTZ losartan/ hydrochlorothiazide, ANOVA one-way analysis of variance
Changes in laboratory tests

Table 2 shows changes in various parameters at the beginning and end of the observation period. There was an increase in serum $\mathrm{Cr}$ concentration (84.9 \pm 34.5 to $89.3 \pm 38.9 \mu \mathrm{mol} / \mathrm{L}, P<0.001)$ in conjunction with a decrease in eGFR (from $65.6 \pm 21.2$ to $63.4 \pm 20.7 \mathrm{~mL}$ / $\left.\mathrm{min} / 1.73 \mathrm{~m}^{2}, P<0.001\right)$. Additionally, there was a significant decrease in serum sodium $(\mathrm{Na})$ concentration (from $141.5 \pm 2.1$ to $140.8 \pm 2.7 \mathrm{mEq} / \mathrm{L}, P<0.001$ ). No changes were found in blood lipids and serum potassium (K) concentration.

Figure 4 depicts changes in BNP after switching from the original prescription to LOS/HCTZ ridden regimen. The overall median BNP level significantly decreased from 18.8 to $15.4 \mathrm{pg} / \mathrm{dL}(P<0.05)$. In patients whose BNP at baseline was more than $18.4 \mathrm{pg} / \mathrm{dL}$ (above the normal range, $n=96)$, the median level of BNP also decreased from 34.4 to $25.4 \mathrm{pg} / \mathrm{dL}(P<0.01)$.

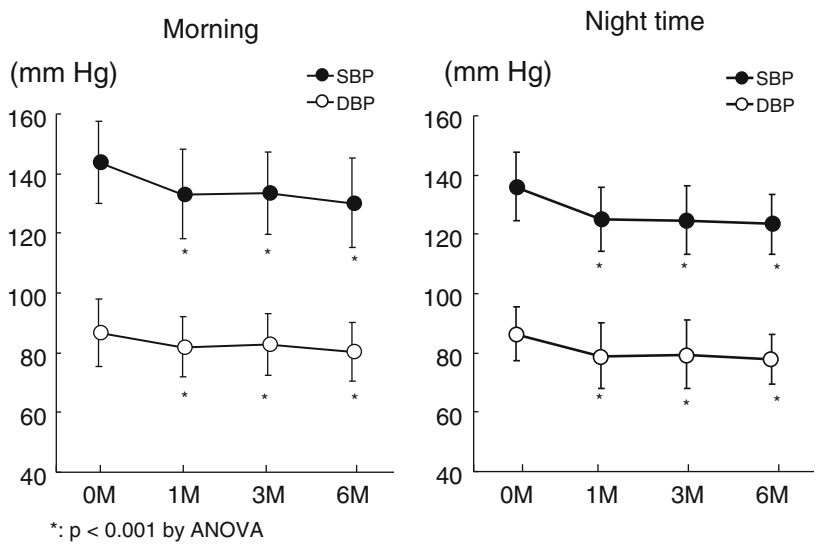

Fig. 3 Effect of LOS/HCTZ on home BP (all patients). SBP systolic blood pressure, DBP diastolic blood pressure, LOS/HCTZ losartan/ hydrochlorothiazide, ANOVA one-way analysis of variance
Fig. 2 Effect of LOS/HCTZ on clinic BP (various switching patterns). $S B P$ systolic blood pressure, $D B P$ diastolic blood pressure, LOS/HCTZ losartan/ hydrochlorothiazide, $C C B \mathrm{Ca}$ channel blockers, ANOVA oneway analysis of variance
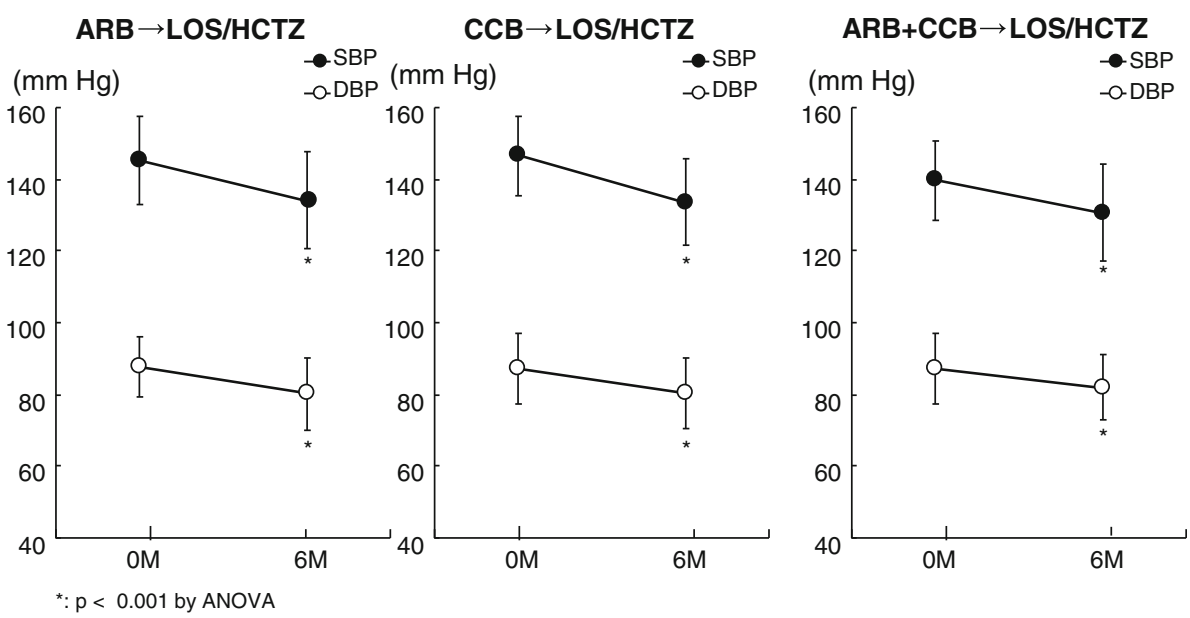
Figure 5 shows the BNP response as a function of BP response. In 135 responders defined as a reduction in systolic BP of $\geq 10 \mathrm{mmHg}$, the median BNP fell from 21.7 to $14.4 \mathrm{pg} / \mathrm{dL}(P<0.05)$, whereas there was no change in BNP in 93 non-responders whose systolic BP reduction was less than $10 \mathrm{mmHg}$.

Figure 6 shows changes in ACR. The overall median value decreased from 21.7 to $13.9 \mathrm{mg} / \mathrm{gCr}(P<0.05)$. In

Table 2 Laboratory tests before and after the treatment with LOS/ HCTZ

\begin{tabular}{lccr}
\hline & \multicolumn{1}{c}{ Baseline } & \multicolumn{1}{c}{6 months } & $P$ value \\
\hline $\mathrm{s}-\mathrm{Cr}(\mu \mathrm{mol} / \mathrm{L})$ & $84.9 \pm 34.5$ & $89.3 \pm 38.9$ & $<0.001$ \\
$\mathrm{Na}(\mathrm{mmol} / \mathrm{L})$ & $141.5 \pm 2.1$ & $140.8 \pm 2.0$ & $<0.001$ \\
$\mathrm{~K}(\mathrm{mmol} / \mathrm{L})$ & $4.3 \pm 0.6$ & $4.3 \pm 0.6$ & 0.940 \\
$\mathrm{LDL}-\mathrm{C}(\mathrm{mmol} / \mathrm{L})$ & $3.0 \pm 0.7$ & $3.0 \pm 0.7$ & 0.356 \\
$\mathrm{HDL}-\mathrm{C}(\mathrm{mmol} / \mathrm{L})$ & $1.5 \pm 0.4$ & $1.5 \pm 0.4$ & 0.118 \\
$\mathrm{TG}(\mathrm{mmol} / \mathrm{L})$ & $1.9 \pm 1.5$ & $1.9 \pm 1.3$ & 0.938 \\
$\mathrm{Hb}(\mathrm{g} / \mathrm{L})$ & $139 \pm 18$ & $139 \pm 17$ & 0.903 \\
$\mathrm{Ht}(\%)$ & $42.1 \pm 4.5$ & $41.8 \pm 4.6$ & 0.141 \\
$\mathrm{RBC}\left(\times 10^{12} / \mathrm{L}\right)$ & $4.49 \pm 0.5$ & $4.47 \pm 0.51$ & 0.428 \\
$\mathrm{WBC}\left(\times 10^{9} / \mathrm{L}\right)$ & $6.2 \pm 1.7$ & $6.3 \pm 1.8$ & 0.508 \\
$\mathrm{Platelets}\left(\times 10^{9} / \mathrm{L}\right)$ & $232 \pm 55$ & $233 \pm 55$ & 0.670 \\
eGFR $\left(\mathrm{mL} / \mathrm{min} / 1.73 \mathrm{~m}^{2}\right)$ & $65.6 \pm 21.2$ & $63.4 \pm 20.7$ & $<0.001$ \\
\hline
\end{tabular}

Laboratory tests before (baseline) and after (6 months) the treatment with LOS/HCTZ

$s$ - $\mathrm{Cr}$ serum creatinine concentration, $\mathrm{Na}$ serum sodium concentration, $K$ serum potassium concentration, $L D L-C$ LDL cholesterol, $H D L-C$ HDL cholesterol, $T G$ triglyceride, $H b$ hemoglobin, $H t$ hematocrit, $e G F R$ estimated glomerular filtration rate patients whose baseline ACR more than $30 \mathrm{mg} / \mathrm{gCr}$ (above the abnormal range, $n=67)$, the median value decreased from 108.0 to $52.0 \mathrm{mg} / \mathrm{gCr}(P<0.01)$.

Changes in ACR between BP responders defined as a reduction in systolic $\mathrm{BP}$ of $\geq 10 \mathrm{mmHg}$ after 6 months and non-responders (systolic $\mathrm{BP}$ reduction $<10 \mathrm{mmHg}$ ) to treatment with LOS/HCTZ were comparable, with a significant reduction in both groups (data not shown).

Figure 7 shows changes in serum UA concentration. Although the fluctuation remained within the normal range, overall serum UA concentration increased $(355 \pm 93$ to $367 \pm 92 \mu \mathrm{mol} / \mathrm{L}, P<0.05)$. When patients were classified into a high-UA group (UA $\geq 416 \mu \mathrm{mol} / / \mathrm{L}$ ) and a lowUA group (UA $<416 \mu \mathrm{mol} / \mathrm{L}$ ), a significant increase was observed in the low-UA group $(315 \pm 65$ to $333 \pm 77 \mu \mathrm{mol} / \mathrm{L}, P<0.01)$. In contrast, in the high-UA group there was a significant decrease in UA value $(473 \pm 47$ to $454 \pm 63 \mu \mathrm{mol} / \mathrm{L}, P<0.05)$.

Changes in BNP, ACR and serum UA levels were analyzed in the presence and absence of CKD (defined as $\mathrm{e}-\mathrm{GRF} \leq 60 \mathrm{~mL} / \mathrm{min} / 1.73 \mathrm{~m}^{2}$ ). The reduction in ACR in the non-CKD group was greater than that in the CKD group (CKD: $-0.12 \pm 0.31 \mathrm{mg} / \mathrm{gCr}$ vs. non-CKD: $-0.24 \pm 0.36 \mathrm{mg} / \mathrm{gCr}, P=0.044)$. No difference in the other parameters was found between the two groups.

Changes in BNP and ACR were also analyzed in conjunction with changes in clinic BP. A significant association was found between the reduction in systolic BP and the decrease in BNP $(r=0.208, P=0.004)$, and ACR ( $r=0.290, P<0.001)$. The reduction in diastolic BP was correlated only with the decrease in ACR $(r=0.291$, $P<0.001)$.
Fig. 4 Changes in BNP in response to LOS/HCTZ. BNP B-type natriuretic peptide, LOS/ HCTZ losartan/ hydrochlorothiazide

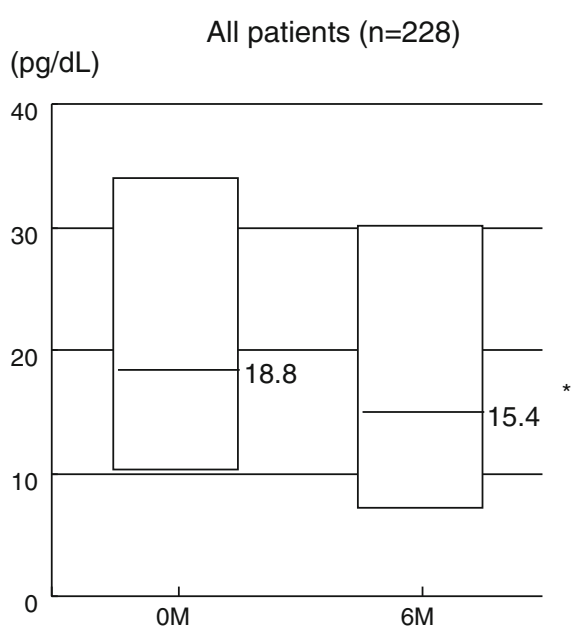

Note: The upper normal limit of BNP is $18.4 \mathrm{pg} / \mathrm{dL}$.
Subgroup analysis

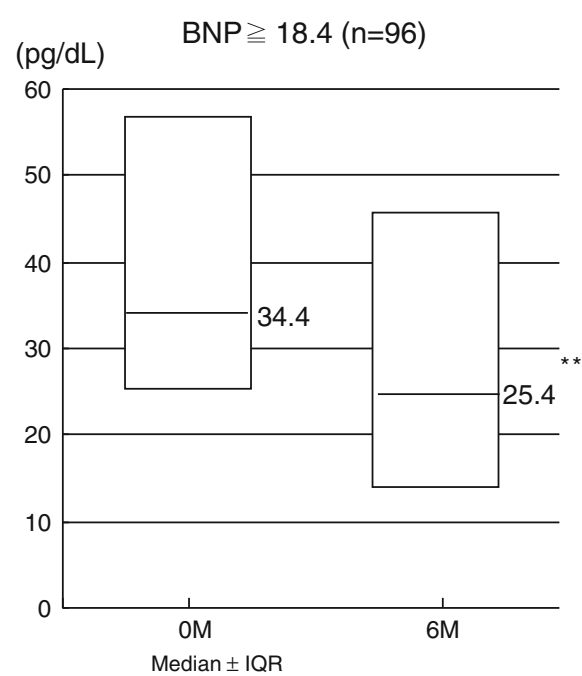

by Wilcoxon signed rank test

*: $p<0.05, \quad$ **: $p<0.01$ 
Fig. 5 Changes in BNP classified by BP response. Responders were defined as patients whose systolic BP reduction was more than $10 \mathrm{mmHg}$. LOS/HCTZ losartan/ hydrochlorothiazide

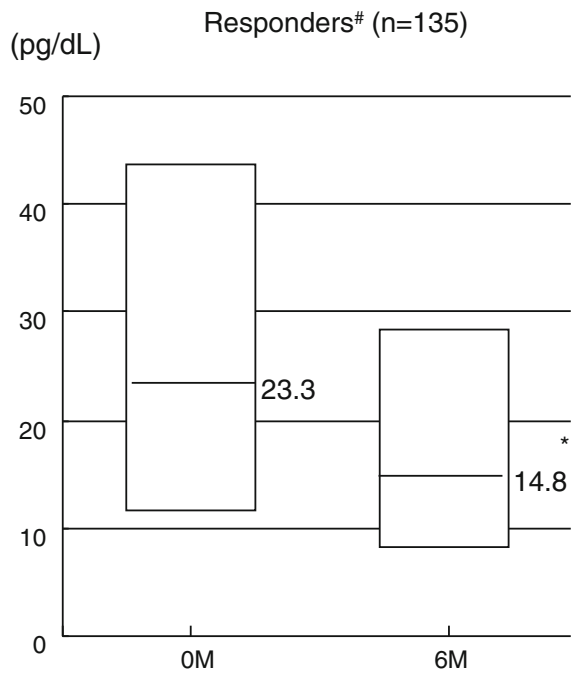

(pg/dL) Non-responders $(\mathrm{n}=93)$

by Wilcoxon signed rank test ${ }^{*}: p<0.05$

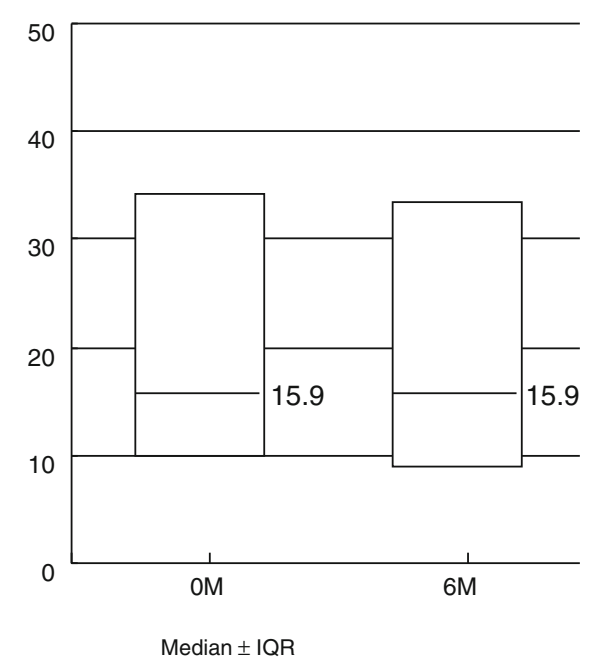

Fig. 6 Changes in ACR in response to LOS/HCTZ. LOS/ HCTZ losartan/

hydrochlorothiazide, $A C R$ albumin creatinine excretion ratio

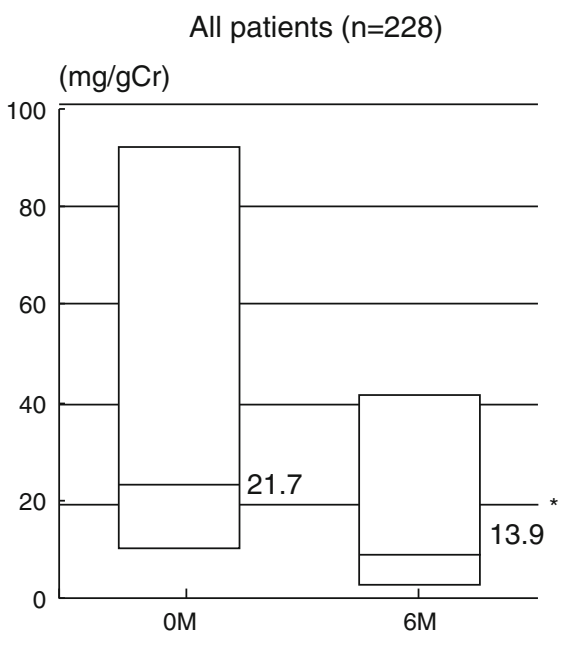

Note: The upper normal limit of $A C R$ is $30 \mathrm{mg} / \mathrm{gCr}$.
Subgroup analysis

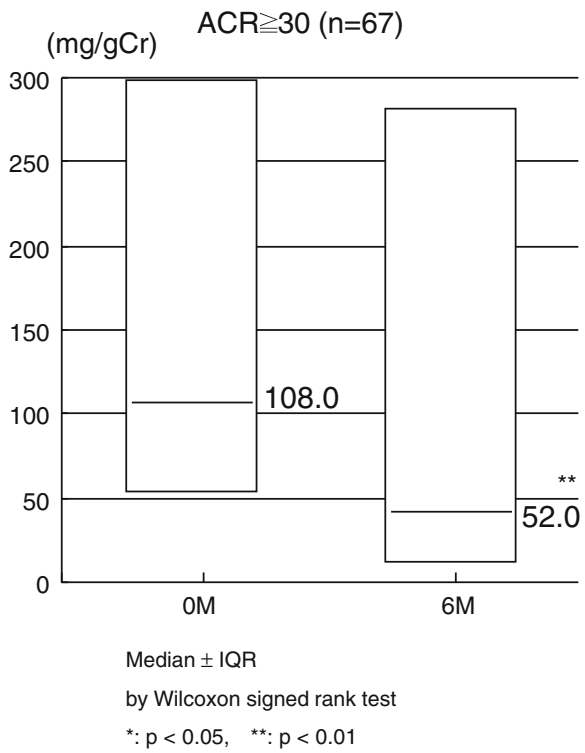

\section{Discussion}

\section{BP lowering effect of LOS/HCTZ}

Similar to the recommendations from hypertension guideline worldwide [1, 4, 11, 12], the guideline of Japanese Society of Hypertension (JSH) recommends the use of diuretics as first-line antihypertensive treatment [5]. A fixed dose combination of LOS/HCTZ which contains normal dose of LOS $(50 \mathrm{mg})$ and a low dose HCTZ $(12.5 \mathrm{mg})$ has lately come into clinical practice. The present study clearly demonstrated that switching to LOS/
HCTZ consistently led to a potent antihypertensive effect regardless of the mode of BP (clinic or home, morning or night: Figs. 1, 2), or the types of the pre-prescribed drugs (switching patterns: Fig. 3). Similar results were reported by Kita et al. [7] in a 1-year study of Japanese patients in which switching from ARBs or ACE-Is to LOS/HCTZ was carried out (The PALM-1 study). Their observation showed that after the treatment with LOS/HCTZ, 50\% of patients fulfilled the targeted goals of the JSH guideline for systolic BP and 79\% for diastolic BP. The achieving rate of $130 / 80 \mathrm{mmHg}$ in the present study $(53 \%)$ coincides with these results. A randomized controlled study reported by 
Fig. 7 Changes in UA in response to LOS/HCTZ UA: serum uric acid concentration. High UA: patients whose serum UA concentration $\geq 416 \mu \mathrm{mol} / /$ L. Low-UA group patients whose serum UA concentration $<416 \mu \mathrm{mol} / \mathrm{L}$

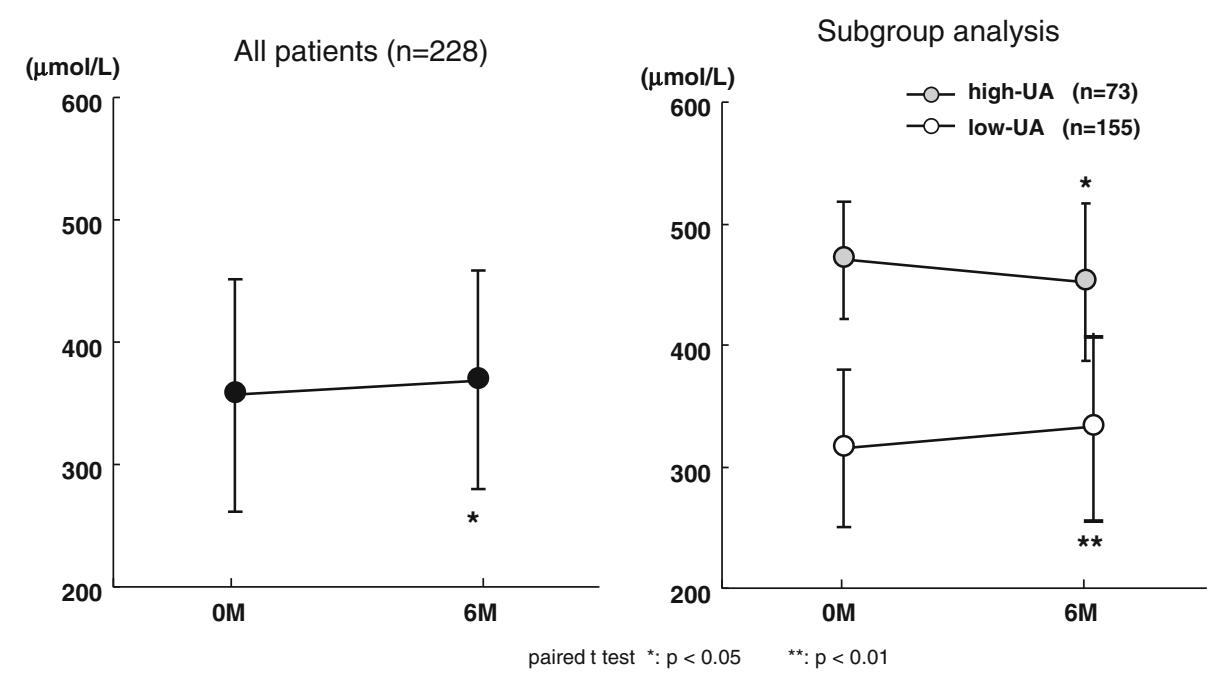

Ando et al. evaluated the effect of telmisartan, an ARB, plus low dose HCTZ compared with an increased dose of amlodipine, a CCB, when switched from amlodipine. The Effect of lowering BP was more profound in the telmisartan plus HCTZ group than in the increased dose of amlodipine group (The ONEAST study) [13].

The potent antihypertensive effect of LOS/HCTZ may partially be derived from the characteristics of the Japanese, whose intake of salt is traditionally high with the main sources including soy sauce, miso, salted fish, and salt added at the table $[14,15]$. Salt-sensitive hypertension is associated with an impaired renal capacity to properly excrete sodium and water, resulting in a therapy-resistant hypertension. Of importance is that high salt suppresses the RAS, thereby diminishing the action of RAS inhibitors. Indeed, in $40-50 \%$ of the essential hypertensive population, adrenal and renal vascular responses to AII do not exhibit the expected changes predicted by changes in sodium intake [15]. In contrast, diuretics potentiate the RAS by contracting circulation volume, leading to an effective BP reduction, especially if salt intake of patients is high. The combination of an ARB and a diuretic is, therefore, considered advantageous in terms of strict BP control in salt sensitive patients with hypertension. Of note is that the present study showed that the responders had higher BP at entry, suggesting "the higher the BP, the better the response" characteristic with the combination of LOS/HCTZ in patients with uncontrolled hypertension.

Effect of LOS/HCTZ on renal function and electrolytes

Although the fluctuations were kept within the normal range, decrease in eGFR in conjunction with increased serum $\mathrm{Cr}$ concentration is a matter for debate. It is apparent that both are attributable to the use of diuretic. Substantial evidences have demonstrated that diuretic reduces GFR.
For instance, studies exploring the effect of ARB/HCTZ repeatedly showed a reduction in eGFR in association with an increase in serum $\mathrm{Cr}$ concentration [7, 16, 17]. Decreased eGFR owing to the use of diuretics could be explained by the contraction of circulating plasma volume. Whether the decreased eGFR is a precipitating factor for the preservation of residual renal function is unknown. However, to date, a large body of reports has confirmed that diuretics are unequivocally efficacious in preventing major cardiovascular events, which include SHEP [18], ALLHAT [19], ACCOMPLISH [20], EWPHE [21], HYVET [22] and ADVANCE [23]. Moreover, a large scale PROBE trial exploring the effect of combination therapy performed in Japan suggested that the diuretic-ridden regimen was effective to prevent composite cardiovascular events [24]. One can, therefore, speculate that both the increased serum $\mathrm{Cr}$ concentration and the decreased eGFR could have been the result of a transient volume contraction due to the use of diuretic.

Although the change was subtle and entirely asymptomatic, the significance of decrease in the serum Na concentration may also be disputable. Adverse effect of hyponatremia is a well-recognized complication of treatment with thiazide that occurs predominantly in patients older than 70 years [25]. Two elements are associates with symptomatic hyponatremia. Such factors are diuretic at higher dosage (HCTZ dose between 35 and $50 \mathrm{mg}$ ) and low salt intake with a preexisting reduction in free water clearance or a high fluid intake [12]. Unless these two conditions meet, serious hyponatremia is unlikely occur particularly if patients are mobile. Uzu et al. [26] showed that treatment with HCTZ $12.5 \mathrm{mg}$ and LOS $50 \mathrm{mg}$ did not induce significant reduction in serum $\mathrm{Na}$ concentration. The present study, however, cast a caution that careful monitoring of serum $\mathrm{Na}$ concentration is indispensable in the treatment with HCTZ, even in a low prescribed dose of $12.5 \mathrm{mg}$. 
With respect to serum $\mathrm{K}$ concentration, our study showed that there was no change in this parameter. Combining LOS with HCTZ exerts a beneficial offsetting effect in $\mathrm{K}$ metabolism, because the former increases serum $\mathrm{K}$ concentration and the latter decreases, diminishing the risk of either hyper-, or hypokalemia.

\section{Effect of LOS/HCTZ on BNP and ACR}

There was a substantial decrease in BNP, a marker for cardiac hypertrophy (Fig. 4). Furthermore, the reduction in BNP was obvious in patients with elevated BNP values and in those who responded well to the therapy, suggesting that the BNP lowering effect depends on BP reduction (Fig. 5). Strict BP control, therefore, appears to be indispensable for cardio-protection.

There was a substantial decrease in ACR, and the effect was profound especially in patients with elevated ACR (Fig. 6). The reno-protective effects of LOS have been demonstrated in the RENAAL study in patients with type 2 diabetic nephropathy [27]. The risk of a doubling of the serum $\mathrm{Cr}$ concentration, end-stage renal disease, or death from any cause, was reduced by about $16-28 \%$ with LOS. In addition, the LIFE study, demonstrating the superiority of LOS over atenolol for reduction of CV morbidity and mortality, was accompanied by the reduction in albuminuria [28-30]. The present study clearly confirmed that treatment with LOS/HCTZ is effective to improve microalbuminuria.

Decreases in BNP and ACR may portend good clinical outcomes for cardio- and reno-protection. However, longer term follow up would be needed to prove such.

\section{Effect of LOS/HCTZ on UA metabolism}

Despite the potent antihypertensive effect, diuretics have been less frequently used in clinical practice for fear of their adverse effects, including increase in serum UA concentration. In the present study, a subtle but significant increase in serum UA concentration was observed in overall patients, although such changes still remained within the normal range (Fig. 7). Of note is that when patients were stratified into a high-UA group and a low-UA group, significant decrease was observed only in the former. The same results were noted in the study by Kita et al. [7] who reported that while UA levels were kept within normal ranges a significant decrease in UA levels was observed in patients with hyperuricemia (The PALM-1 study). A recent post hoc analysis also confirmed that LOS lowers serum UA levels compared with placebo in patients with diabetic nephropathy [31]. The mechanisms by which LOS/HCTZ reduces UA levels in patients with hyperuricemia is largely attributable to uricosuric action of LOS, which has been known to be mediated by the inhibition of the UA transporter URAT-1 in the renal tubules $[8,9]$. In the high-UA group, the uricosuric action of LOS might offset the hyperuricemic action of HCTZ, resulting in a decreased UA level in the high-UA group.

Limitation of the present study

The present study has limitation. It is not a randomized controlled study and no control group was used. Further study in a randomized, controlled fashion will help to strengthen the findings of this study.

In conclusion, a fixed dose combination formula of LOS plus HCTZ is efficacious in achieving BP goal in patients with uncontrolled hypertension. In addition, cardio-, renoprotective effects may also be anticipated.

Acknowledgments The authors would like to thank all of the investigators for their participation in the JOINT study. We also appreciate comments and suggestions of Prof. Robert Toto, Southwestern Medical School, Dallas, USA. The JOINT was supported by a grant from the Kidney Foundation, Japan.

\section{Conflict of interest None.}

Open Access This article is distributed under the terms of the Creative Commons Attribution Noncommercial License which permits any noncommercial use, distribution, and reproduction in any medium, provided the original author(s) and source are credited.

\section{Appendix}

The JOINT stands for The Jikei Optimal Antihypertensive Treatment Study, which included the following investigators in addition to the members listed on the title: Endo $\mathrm{S}$, Fukui A, Gomi H, Hamaguchi A, Hanaoka K, Hara Y, Hara Y, Hasegawa T, Hayakawa H, Hikida M, Hirano K, Horiguchi M, Hosoya M, Ichida K, Imai T, Ishii T, Ishikawa H, Kameda C, Kasai T, Kobayashi A, Kobayashi H, Kurashige M, Kusama Y, Maezawa H, Maezawa Y, Maruyama Y, Matsuda H, Matsuo N, Matsuo T, Miura Y, Miyajima M, Miyakawa M, Miyazaki Y, Mizuguchi M, Nakao M, Nokano H, Ohkido I, Ohtsuka Y, Okada K, Okamoto H, Okonogi H, Saikawa H, Saito H, Sekiguchi C, Suetsugu Y, Sugano N, Suzuki T, Suzuki T, Takahashi H, Takahashi Y, Takamizawa S, Takane K, Morita T, Takazoe K, Tanaka H, Tanaka S, Terawaki H, Toyoshima R, Tsuboi $\mathrm{N}$, Udagawa $\mathrm{T}$, Ueda $\mathrm{H}$, Ueda $\mathrm{Y}$, Uetake $\mathrm{M}$, Unemura $\mathrm{S}$, Utsunomiya M, Utsunomiya Y, Yamada T, Yamada Y, Yamaguchi Y, Yamamoto H,Yokoo T, Yokoyama K, Yonezawa H, Yoshida H, Yoshida M and Yoshizawa T. 


\section{References}

1. World Health Organization, International Society of Hypertension Writing Group. 2003 World Health Organization (WHO)/ International Society of Hypertension (ISH) statement on management of hypertension. J Hypertens. 2003;21:1983-92.

2. Ohkubo T, Obara T, Funahashi J, Kikuya M, Asayama K, Metoki H, Oikawa T, Takahashi H, Hashimoto J, Totsune K, Imai Y. Control of blood pressure as measured at home and office, and comparison with physicians' assessment of control among treated hypertensive patients in Japan: first report of the Japan Home versus Office Blood Pressure Measurement Evaluation (J-HOME) study. Hypertens Res. 2004;27:755-63.

3. Waeber B. Achieving blood pressure targets in the management of hypertension. Blood Press Suppl. 2001;2:6-12.

4. Chobanian AV, Bakris GL, Black HR, Cushman WC, Green LA, Izzo JL, Jr, Jones DW, Materson BJ, Oparil S, Wright JT, Jr, Roccella EJ, and the National High Blood Pressure Education Program Coordinating Committee. National Heart, Lung, and Blood Institute Joint National Committee on Prevention, Detection, Evaluation, and Treatment of High Blood Pressure; National High Blood Pressure Education Program Coordinating Committee: the seventh report of the Joint National Committee on Prevention, Detection, Evaluation, and Treatment of High Blood Pressure: the JNC 7 report. JAMA. 2003;289:2560-72.

5. Ogihara T, Kikuchi K, Matsuoka H, Fujita T, Higaki J, Horiuchi M, Imai Y, Imaizumi T, Ito S, Iwao H, Kario K, Kawano Y, KimMitsuyama S, Kimura G, Matsubara H, Matsuura H, Naruse M, Saito I, Shimada K, Shimamoto K, Suzuki H, Takishita S, Tanahashi N, Tsuchihashi T, Uchiyama M, Ueda S, Ueshima H, Umemura S, Ishimitsu T, Rakugi $\mathrm{H}$, on behalf of The Japanese Society of Hypertension Committee. The Japanese Society of Hypertension Guidelines for the Management of Hypertension (JSH 2009). Hypertens Res. 2009;32:3-107.

6. Bakris GL, Williams M, Dworkin L, Elliott WJ, Epstein M, Toto R, Tuttle K, Douglas J, Hsueh W, Sower J. Preserving renal function on adults with hypertension ans diabetes: a consensus approach. National Kidney Foundation Hypertension and Diabetes Executive Committees Working Group. Am J Kidney Dis. 2000;36:646-61.

7. Kita T, Yokota N, Ichiki Y, Ayabe T, Etoh T, Tamaki N, Kato J, Eto T, Kitamura K. One-year effectiveness and safety of openlabel losartan/hydrochlorothiazide combination therapy in Japanese patients with hypertension uncontrolled with ARBs or ACE inhibitors. Hypertens Res. 2010;33:320-5.

8. Enomoto A, Kimura H, Chairongudua A, Shigeta Y, Jutabha P, Cha SH, Hosoyamada M, Takeda M, Sekine T, Igarashi T, Matsuo H, Kikuchi Y, Oda T, Ichida K, Hosoya T, Shimokata K, Niwa T, Kanai Y, Endou H. Molecular identification of a renal urate exchanger that regulates blood urate levels. Nature. 2002;417:447-52.

9. Anzai N, Ichida K, Jutabha P, Kimura T, Babu E, Jin CJ, Srivastava S, Kitamura K, Hisatome I, Endou H, Sakurai H. Plasma urate level is directly regulated by a voltage-driven urate efflux transporter URAT-1 (SLC2A9) in humans. J Biol Chem. 2008;283:26834-8.

10. Frohlich ED, Grim C, Labarthe DR, Maxell MH, Perloff D, Weidman WH. Recommendation for human blood pressure determination by sphygmomanometers. Hypertension. 1988;11: 209A-22A

11. Mori H, Ukai H, Yamamoto H, Saitou S, Hirao K, Yamauchi M, Umemura S. Current status of antihypertensive prescription and associated blood pressure control in Japan. Hypertens Res. 2006;29:143-51.
12. Stafford RS, Bartholomew LK, Cushman WC, Cutler JA, Davis BR, Dawson G, Einhorn PT, Furberg CD, Piller LB, Pressel SL, Whelton PK. Impact of the ALLHAT/JNC7 Dissemination Project on thiazide-type diuretic use. Arch Intern Med. 2010;170:851-8.

13. Ando K, Isshiki $M$, Takahashi $K$. Effect of switching from amlodipine to combination therapy with telmisartan and low-dose hydrochlorothiazide. Hypertens Res. 2009;32:748-52.

14. Brown IJ, Tzoulaki I, Candeias V, Elliott P. Salt intakes around the world: implications for public health. Int $\mathrm{J}$ Epidemiol. 2009;38:791-813.

15. Drenjančević-Perić I, Jelaković B, Lombard JH, Kunert MP, Kibel A, Gros M. High-salt diet and hypertension: focus on the renin-angiotensin system. Kidney Blood Press Res. 2011;34:1-11.

16. Racine N, Hamet P, Sampalis JS, Longo N, Bastien N. A 52-week prospective, cohort study of the effects of losartan with or without hydrochlorothiazide (HCTZ) in hypertensive patients with metabolic syndrome. J Hum Hypertens. 2010;24:739-48.

17. Liou YS, Ma T, Tien L, Lin CM, Jong GP. The relationship between antihypertensive combination therapies comprising diuretics and/or beta-blockers and the risk of new onset diabetes: a retrospective longitudinal cohort study. Hypertens Res. 2009;32:496-9.

18. Kostis JB, Davis BR, Cutler J, Grimm RH Jr, Berge KG, Cohen JD, Lacy CR, Perry HM Jr, Blaufox MD, Wassertheil-Smoller S, Black HR, Schron E, Berkson DM, Curb JD, Smith WM, McDonald R, Applegate WB. Prevention of heart failure by antihypertensive drug treatment in older persons with isolated systolic hypertension. JAMA. 1997;278:212-6.

19. The ALLHAT Officers Coordinators for the ALLHAT Collaborative Research Group. Major outcomes in high-risk hypertensive patients randomized to angiotensin-converting enzyme inhibitor or calcium channel blocker vs diuretic: The Antihypertensive and Lipid-Lowering Treatment to Prevent Heart Attack Trial (ALLHAT). JAMA. 2002;288:2981-97.

20. Jamerson K, Weber MA, Bakris GL, Dahlöf B, Pitt B, Shi V, Hester A, Gupte J, Gatlin M, Velazquez EJ, for the ACCOMPLISH Trial Investigators. Benazepril plus amlodipine or hydrochlorothiazide for hypertension in high-risk patients. N Engl J Med. 2008;359:2417-28.

21. Amery A, Brixko P, Clement D, De Schaepdryver A, Fagard R, Forte J, Henry JF, Leonetti G, O'Malley K, Strasser T, Birkenhäger $\mathrm{W}$, Bulpitt $\mathrm{C}$, Deruyttere $\mathrm{M}$, Dollery C, Forette F, Hamdy R, Joossens JV, Lund-Johansen P, Petrie J, Tuomilehto J, Williams B. Mortality and morbidity results from the European working party on high blood pressure in the elderly trial. Lancet. 1985;325:1349-54.

22. Beckett NS, Ch B, Peters R, Fletcher AE, Staessen JA, Liu L, Dumitrascu D, Stoyanovsky V, Antikainen RL, Nikitin Y, Anderson C, Belhani A, Forette F, Rajkumar C, Thijs L, Banya W, Bulpitt CJ, for the HYVET Study Group. Treatment of hypertension in patients 80 years of age or older. N Engl J Med. 2008;358:1887-98.

23. Patel A, ADVANCE Collaborative Group, MacMahon S, Chalmers J, Neal B, Woodward M, Billot L, Harrap S, Poulter N, Marre M, Cooper M, Glasziou P, Grobbee DE, Hamet P, Heller S, Liu LS, Mancia G, Mogensen CE, Pan CY, Rodgers A, Williams B. Effects of a fixed combination of perindopril and indapamide on macrovascular and microvascular outcomes in patients with type 2 diabetes mellitus (the ADVANCE trial): a randomised controlled trial. Lancet. 2007;370:829-40.

24. Ogihara T, Matsuzaki M, Umemoto S, Rakugi H, Matsuoka H, Shimada K, Abe K, Suzuki N, Eto T, Higaki J, Ito S, Kamiya A, Kikuchi K, Suzuki H, Tei C, Ohashi Y, Saruta T, for the COPE 
Trial Group. Prevention of cardiovascular events with calcium antagonist-based combination therapies in patients with hypertension: a randomized controlled trial-combination therapy of hypertension to prevent cardiovascular events (COPE) trial (abstract). Presented at the International Society of Hypertension in Vancouver, 2010.

25. Mann SJ. The silent epidemic of thiazide-induced hyponatremia. J Clin Hypertens. 2008;10(6):477-84.

26. Uzu T, Sakaguchi M, Yokomaku Y, Kume S, Kanasaki M, Isshiki K, Araki S, Sugimoto T, Koya D, Haneda M, Kashiwagi A. Effect of high salt intake and diuretics on the circadian rhythm of blood pressure in type 2 diabetic patients treated with an angiotensin II receptor blocker. Clin Exp Nephrol. 2009;13:300-6.

27. Brenner BM, Cooper ME, de Zeeuw D, Keane WF, Mitch WE, Parving HH, Remuzzi G, Snapinn SM, Zhang Z, Shahinfar S, RENAAL Study Investigators. Effects of losartan on renal and cardiovascular outcomes in patients with type 2 diabetes and nephropathy. N Engl J Med. 2001;345:861-9.

28. Dahlöf B, Devereux RB, Kjeldsen SE, Julius S, Beevers G, de Faire U, Fyhrquist $\mathrm{F}$, Ibsen $\mathrm{H}$, Kristiansson $\mathrm{K}$, LederballePedersen O, Lindholm LH, Nieminen MS, Omvik P, Oparil S, Wedel H, LIFE Study Group. Cardiovascular morbidity and mortality in the Losartan Intervention For Endpoint reduction in hypertension study (LIFE): a randomised trial against atenolol. Lancet. 2002;359:995-1003.

29. Ibsen H, Olsen MH, Wachtell K, Borch-Johnsen K, Lindholm LH, Mogensen CE, Dahlöf B, Snapinn SM, Wan Y, Lyle PA. Does albuminuria predict cardiovascular outcomes on treatment with losartan versus atenolol in patients with diabetes, hypertension, and left ventricular hypertrophy? The LIFE study. Diabetes Care. 2006;29:595-600.

30. Matsui Y, Eguchi K, Ishikawa J, Shimada K, Kario K. Urinary albumin excretion during angiotensin II receptor blockade: comparison of combination treatment with a diuretic or a calcium-channel blocker. Am J Hypertens. 2010. doi:10.1038/ajh. 2010.240.

31. Miao Y, Ottenbros SA, Laverman GD, Brenner BM, Cooper ME, Parving H-H, Grobbee DE, Shahnas S, Zeeuw ME, Heerspink HJL. Effect of a reduction in uric acid on renal outcomes during losartan treatment: a post hoc analysis of the reduction of endpoints in non-insulin-dependent diabetes mellitus with the angiotensin II antagonist losartan trial. Hypertension. 2011;58: $2-7$. 